\title{
Value Based Strategic Distributed Generator Placement by Particle Swarm Optimization
}

\author{
G. Bala Krishna ${ }^{1}$, Dr.Ch. Sai Babu ${ }^{2}$, \\ 1. Associate Professor, Department of Electrical Engineering, Intell Engineering College, Anantapur \\ 2. Professor in Electrical Engineering Department, JNTU College of Engineering, Kakinada
}

\begin{abstract}
Now a days the technology adopted for power generation, transmission and distribution in a power system changing continuously from day to day. At the same time the load demand at the distribution levels also experiencing great changes continuously from time to time. This situation leads to the additional resources which will meet the increasing load demand at the distribution levels. One of the best solutions for this problem is Distributed Generation (DG). Proper selection of DG location and size surely gives the benefits in terms of enhancement of reliability and reduction of losses. But at the same time it is required to spend some amount of money towards installing the $D G$ which can be treated as cost of DG. The method proposed in this work tries to find the best balance between the Cost and benefit of the DG placement. In this work the main aim is to find the optimal locations and sizes in the distribution feeders. The results have shown that with proper sizes and locations, DG can be used to improve service reliability, reduces the customer interruption costs and saves the power losses. Particle swarm Optimization Technique was used to solve the above problem.
\end{abstract}

Key words: Distributed generatiors, value based, value based, customer interruption cost, Particle Swarm Optimization

\section{Introduction:}

There are many methods available for DG placements and planning. [1] Reported some successive experiences of DG happed in Central Virginia Electric Cooperative. [2] Proposed a method for DG planning based on genetic algorithm. The paper aimed on the cost evaluation. The benefits for customers and utility such as reliability enhancement, customer interruption cost reduction and peaking load cost reduction were not included in the paper. [3] Proposed some processes for DG planning that also permit the incorporation of distribution automation and demand side management. [4] Proposed some guidelines for DG planning. From those papers, we can found that in a deregulated power system, each individual distribution may want to determine the costs and benefits of DG planning in different manners and decisions. It is difficult to find out a single configuration and consideration of planning method that can satisfy every situation and system. In this paper a value-based planning method for DG placement is proposed. This method takes the benefits and costs of DG placement into account and tries to find the optimal location and sizing for DG placement.

In this method value based planning is adopted to solve for the optimal DG placement. This value based planning methods are based on balancing the cost to a utility and the benefits received by the utility and its customers. The cost of the DG placement generally includes the initial cost of DG i.e. investment cost or capital cost, running cost i.e. maintenance and operating cost. The benefits of the DG include the cost of power generated, cost of loss reduction and reliability enhancement in terms of reduction in customer interruption cost. The value based planning method attempts to locate the minimum cost solution where the total benefits can be maximized. The cost of DG placement shows as more money is spent to install more DG capacity, then utility revenue increases, the customer cost decreases and the distribution system reliability increases. The customer cost which is nothing but reliability worth can be the customer interruption cost (CIC) [5]. In this method we choose the CIC as customer cost in our planning and CIC is calculated for any system by the method given in [6].

\section{Formulation Of Problem And Solution}

The main problem studied here is to find the optimal types of DG and their corresponding sizes and locations in distribution feeders. The objective function of the value based DG placement problem is defined as follow:

$$
\begin{aligned}
& \text { Maximize (Benefit }{ }^{\mathrm{DG}} / \mathrm{Cost}^{\mathrm{DG}} \text { ) } \\
& \text { Benefit }{ }^{D G}=K_{A}\left(\Delta P_{\text {loss }}^{\text {avg }}+\sum_{i=1}^{N_{G}} D G_{\text {gen }, i}^{\text {avg }}\right) * C P V 1+\left(C I C^{o}-C I C^{D G}\right) * C P V 2 \\
& \operatorname{Cost}^{D G}=\sum_{i=1}^{N_{G}} \operatorname{Cost}_{i n v, i}+\sum_{i=1}^{N_{G}}\left(\operatorname{Cost}_{\text {oper }, i}+\text { Cost }_{\text {main }, i}\right) * \operatorname{CPV} 1
\end{aligned}
$$

Where Benefit ${ }^{\mathrm{DG}}$ and cost ${ }^{\mathrm{DG} \text { are }}$ the benefits and costs of DG placements, respectively. $\mathrm{N}_{\mathrm{G}}$ is the total number of DG installed in the feeder, $\mathrm{K}_{\mathrm{A}}$ is the cost of energy (in Rs./kW.h). $\Delta P_{\text {loss }}^{\text {avg }}$ is the average power loss reduction 
per year due to the DG placement. $D G_{g e n, i}^{a v g}$ is the average power generation of $\mathrm{i}^{\text {th }} \mathrm{DG}$ per year. $\mathrm{CIC}^{\mathrm{O}}$ and $\mathrm{CIC}^{\mathrm{DG}}$ are the CIC of a distribution feeder before and after connecting DG, Cost $_{\mathrm{nvv}, \mathrm{i}}$, Cost $_{\mathrm{main}, \mathrm{i}}$ and Cost ${ }_{\text {oper, } \mathrm{i}}$ are the investments, maintenance and operating costs of $\mathrm{i}^{\text {th }} \mathrm{DG}$ per year. CPV is the cumulative present value.

In the equations (2), (3) since most costs are the future annual costs, it needs the CPV to discount the value of future costs. For the cost of maintenance, operating and power loss and cost reduction, the CPV1 needs to take the interest rate, inflation rate, and economic life of equipment into account. For CIC, the CPV2 needs to incorporate the interest rate, inflation rate, load growth rate and economic life of equipment.

Feeder failure rate and load distributions are considered in the above formulations. The minimum acceptable benefit/cost ratio, voltage drop, feeder load transfer capability should also be considered i.e

$$
\begin{aligned}
& V_{j} \geq V^{\min } \\
& \sum_{i \in \emptyset} P_{i} \leq \Delta P^{\max }
\end{aligned}
$$

$\Delta P^{\max }$ is the available load transfer capability and $\emptyset$ is the set of sections temporarily served by the neighboring feeders. $\mathrm{Vj}$ is the bus voltage and $\mathrm{V}^{\mathrm{min}}$ is the minimum allowable bus voltage.

The selection of proper types of DG and their corresponding locations and sizes is a difficult task in distribution planning because the problem involved is a combinatorial constrained problem with a non-linear and non-differential objective function. Several artificial intelligent algorithm techniques such as genetic algorithm, simulated annealing, evaluation programming and tabu search etc., can be used to solve the problem. In this work, we employed the Particle Swarm Optimization (PSO) to solve the DG placement problem.

\subsection{Introduction:}

\section{Particle Swarm Optimization}

Particle Swarm Optimization (PSO) is a population based optimization method first proposed by Kennedy and Eberhart in 1995, inspired by social behavior of bird flocking or fish schooling [7]. The PSO as an optimization tool provides a population based search procedure in which individuals called particles change their position termed as state with time. In a PSO system, particles fly around in a multidimensional search space. During flight, each particle adjusts its position according to its own experience (is called as Pbest), and according to experience of a neighboring particle (is called Gbest), made use of the best position encountered by itself and its neighbor. This modification can be represented by the concept of velocity. Velocity of each agent can be modified by the equation

$$
V_{i d}^{k+1}=\omega \cdot V_{i d}^{k}+C 1 * \operatorname{rand}() *\left(\text { Pbest }_{i d}-S_{i d}^{k}\right)+C 2 * \text { rand } *\left(\text { Gbest }_{i d}-S_{i d}^{k}\right)
$$

Using the above equation a certain velocity which gradually gets close to Pbest and Gbest can be calculated. The current position (searching point in the solution space) can be modified by the equation

$$
S_{i d}^{k+1}=S_{i d}^{k}+v_{i d}^{k+1}, i=1,2 \ldots \ldots \text { and } d=1,2 \ldots \ldots m \quad \text { (7) }
$$

Where $S^{k}$ is current searching point, $S^{k+1}$ is modified searching point, vk is current velocity, $V^{k+1}$ is modified velocity agent based on Gbest, $\mathrm{n}$ is the number of particles in a group, $\mathrm{m}$ is number of members in a particle, Pbest $_{\mathrm{i}}$ is Pbest of agent "i", Gbesti is Gbest of agent " $\mathrm{i}$ ", $\mathrm{C}_{\mathrm{i}}$ is weight coefficients for each term.

$$
\text { The weight function used is } \omega_{i}=\omega_{\max }-\frac{\omega_{\max }-\omega_{\min }}{\omega_{\max }} \cdot k
$$

Where $\omega_{\min }$ and $\omega_{\max }$ are the minimum and maximum weights respectively, $\mathrm{k}$ and $\mathrm{k}_{\max }$ are the current and maximum iteration. Appropriate values o $\mathrm{C}_{1}$ and $\mathrm{C}_{2}$ are 1 to 2 , but 2 is the most appropriate in many cases. Appropriate values for $\omega_{\min }$ and $\omega_{\max }$ are 0.4 and 0.9 respectively

\subsection{PSO ALGORITHM for VALUE BASED DG PLANNING:}

In this section, an algorithm based on Particle Swarm Optimization (PSO) for solving the Value Based DG placement is described and is as follows:

Let

$$
X_{k}=\left\{\begin{array}{r}
{[x, y, z], x i \in\{1,2, \ldots . P\}, i=1,2 \ldots . N_{G}, \quad y i \in\{1,2, \ldots \ldots . Q\}} \\
z j=\{1,2, \ldots \ldots \ldots R\}
\end{array}\right.
$$

be the trial vector representing $k^{\text {th }}$ particle of the population and $k=1,2,3, \ldots \ldots . . N p$.

Where $\mathrm{X}$ is the Location List of each chromosome,

$P$ is the Number of Candidate DG locations

$\mathrm{Np}$ is the number of populations

$\mathrm{N}_{\mathrm{G}}$ is the Number of DGs

$\mathrm{Q}$ is the Number of types of DGs available

$\mathrm{R}$ is the Number of capacities of DGs available

The algorithm to find the optimal locations, types, sizes of the DGs:

1. Input line data and bus data. 
2. Calculate the power loss using distribution load flow based on backward and forward sweep and customer interruption cost (CIC) for the original configuration of the system.

3. Randomly generate the initial population (array) of particles with random positions and velocities on dimensions in the solutions space. Set the iteration count $\mathrm{k}=0$.

4. For each particle if the bus voltages are within the limits calculate the power loss, cost and cost using the equations (2) and (3) and hence calculate the Benefit/Cost ratio.

5. For each particle compare its objective value with the individual best. If the objective value is lower than Pbest, set this value as the current Pbest, and record the corresponding particle position.

6. Choose the particle associated with the minimum individual best Pbest of all the particles and set the value of this Pbest as the current overall best Gbest.

7. Update the velocities and position of the particle using (6) and (7) respectively.

8. If the iteration number reaches the maximum limit go to setp 9. Otherwise set iteration index $\mathrm{k}=\mathrm{k}+1$ and go back to step 4 .

9. Print the optimal solution to the target problem. The best position includes the optimal locations and size of the single DG or multiple DG and the corresponding fitness value (benefit/cost ratio) and voltage profile corresponding to best solution.

In this work the PSO is mainly used to identify the optimal location of DG that gives us the best Benefit/Cost Ratio subjected to a voltage magnitude constraint and the available load transfer capability of a neighboring substation for one DG, Two DGs and three DGs.

\section{Examples}

The proposed Value based DG placement by PSO is tested on two test systems viz., IEEE 12 and IEEE 33 bus systems and results presented.

The proposed algorithm has been implemented in MATLAB 7.0 version on Pentium IV, 2.4 GHZ Personnel Computer with 2 GB RAM.

For each test system, 50 trails were performed using the proposed method to observe the solution quality, convergence characteristic, and execution time. The parameters used in PSO to get the optimal solution of the problem are given in Table 1.

Table.1: PSO parameters and their setting values for solving value Based optimal DG placement problem

\begin{tabular}{|l|c|}
\hline \multicolumn{1}{|c|}{ PSO Parameters } & Value \\
\hline Population size & 10 \\
\hline Number of generations & 100 \\
\hline Initial weight function, $w_{\max }$ & 0.9 \\
\hline Final weight function, $w_{\min }$ & 0.2 \\
\hline Acceleration constants, $\mathrm{C}_{1,} \mathrm{C}_{2}$ & 2,2 \\
\hline
\end{tabular}

The optimal locations of DGs for one DG, two DGs and three DGs are given Table 2. Real Power Losses before and after DG placement are presented in Table 4 and it has been observed that when DGs are located at its optimal locations the losses in the system decreases considerably. Benefit/cost ratios after placing DG's are presented in Table 3. The convergence Characteristics of PSO for one DG, Two DG and three DGs are given in figures 1 to figure 6 for IEEE 12 and IEEE-33 bus systems

Table 2: Optimal Locations of DGs for IEEE 12 Bus System for one DG, two DGs and three DGs

\begin{tabular}{|c|c|c|c|c|c|c|c|c|}
\hline S.No. & Test System & $\begin{array}{l}\text { No. of } \\
\text { DGs }\end{array}$ & $\begin{array}{l}\text { Location of } \\
\text { First DG }\end{array}$ & $\begin{array}{c}\text { DG } \\
\text { Type }\end{array}$ & $\begin{array}{l}\text { Location of } \\
\text { Second DG }\end{array}$ & $\begin{array}{l}\text { DG } \\
\text { Type }\end{array}$ & $\begin{array}{c}\text { Location of } \\
\text { Third DG }\end{array}$ & DG Type \\
\hline \multirow{3}{*}{1} & \multirow{3}{*}{ IEEE 12 Bus } & 1 & 10 & 3 & \multicolumn{4}{|c|}{ Not Applicable } \\
\hline & & 2 & 7 & 1 & 10 & 2 & \multicolumn{2}{|c|}{ Not Applicable } \\
\hline & & 3 & 7 & 1 & 10 & 2 & 12 & 4 \\
\hline \multirow{3}{*}{2} & \multirow{3}{*}{ IEEE 33 Bus } & 1 & 6 & 3 & \multicolumn{4}{|c|}{ Not Applicable } \\
\hline & & 2 & 6 & 1 & 28 & 2 & \multicolumn{2}{|c|}{ Not applicable } \\
\hline & & 3 & 6 & 1 & 13 & 2 & 28 & 3 \\
\hline
\end{tabular}

From Table 3, the Benefit/Cost Ratio is observed to be higher for one DG because as it is required to spend less amount to install one DG, cost of DG will be low and as we increase the number of DGs to be used in the system the cost of the system increases which in turn decreases the Benefit/Cost ratio. 
Table3: Benefit/cost ratios after placing DG's

\begin{tabular}{|c|c|c|c|}
\hline S.No & Test System & DG No & Benefit/cost Ratio \\
\hline 1 & \multirow{3}{*}{ IEEE 12 Bus System } & $1 \mathrm{DG}$ & 1.339887 \\
\hline 2 & & $2 \mathrm{DG}$ & 1.250715 \\
\hline 3 & & $3 \mathrm{DG}$ & 1.167318 \\
\hline 4 & \multirow{3}{*}{ IEEE 33 Bus System } & $1 \mathrm{DG}$ & 1.339086 \\
\hline 5 & & $2 \mathrm{DG}$ & 1.245836 \\
\hline 6 & & $3 \mathrm{DG}$ & 1.153172 \\
\hline
\end{tabular}

From the Table 4 it is observed that when one DG is placed the losses are reduced by $47.99 \%$ and is increases to $48.62 \%$ when two DGs are placed and is further increased to $48.81 \%$ when three DGs are placed for IEEE 12 bus system and for IEEE-33 bus system the losses are reduced by $47.37 \%$ for one DG, and reduction in losses is increased to $66.84 \%$ for two DGs and is further increased to $70.63 \%$ for three DGs.

Table 4: Power Losses before and after DG placement

\begin{tabular}{|c|c|c|c|c|c|c|}
\hline S.No. & Test System & $\begin{array}{l}\text { No. of } \\
\text { DGs }\end{array}$ & $\begin{array}{c}\text { Power Losses } \\
\text { before } \\
\text { DG(MW) }\end{array}$ & $\begin{array}{l}\text { Power Losses } \\
\text { after DG(MW) }\end{array}$ & $\begin{array}{l}\text { Reduction in } \\
\text { Power losses }\end{array}$ & $\begin{array}{c}\text { \% Reduction in } \\
\text { Losses }\end{array}$ \\
\hline \multirow{3}{*}{1} & \multirow{3}{*}{$\begin{array}{l}\text { IEEE } 12 \\
\text { Bus }\end{array}$} & 1 & \multirow{3}{*}{0.02069} & 0.01076 & 0.00993 & 47.99 \\
\hline & & 2 & & 0.01059 & 0.0101 & 48.81 \\
\hline & & 3 & & 0.01063 & 0.01006 & 48.62 \\
\hline \multirow{3}{*}{2} & \multirow{3}{*}{$\begin{array}{l}\text { IEEE } 33 \\
\text { Bus }\end{array}$} & 1 & \multirow{3}{*}{0.21100} & 0.11103 & 0.09997 & 47.37 \\
\hline & & 2 & & 0.06996 & 0.14104 & 66.84 \\
\hline & & 3 & & 0.06195 & 0.14905 & 70.63 \\
\hline
\end{tabular}

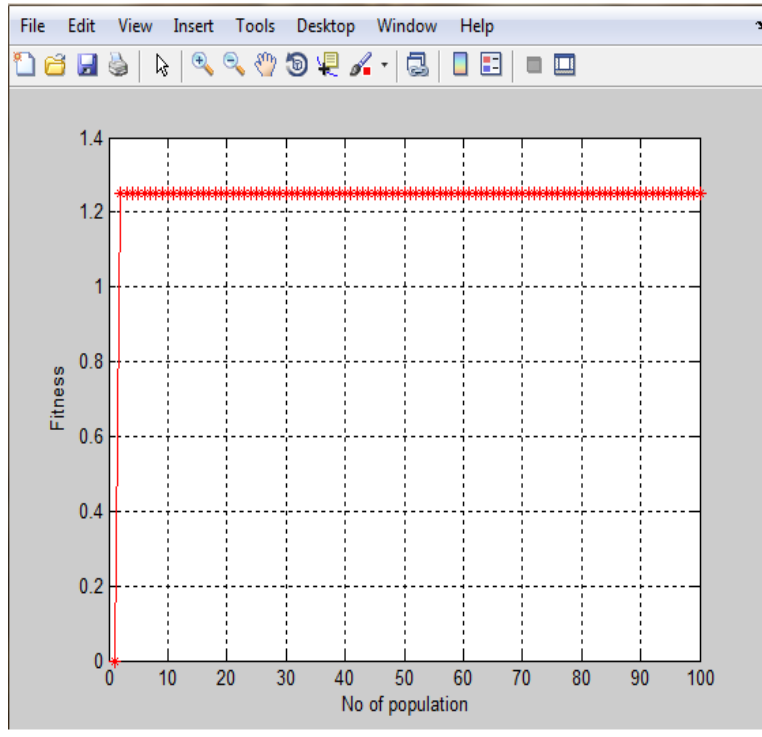

figure 1. Convergence Characteristics of PSO for One DG for IEEE 12 Bus System

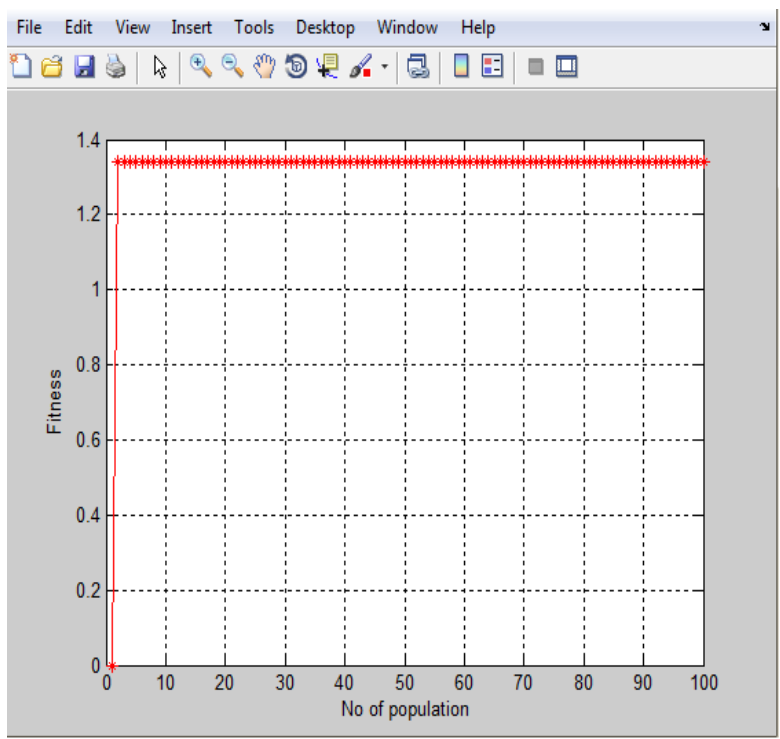

Figure 2. Convergence Characteristics of PSO for two DG for IEEE12 Bus system 


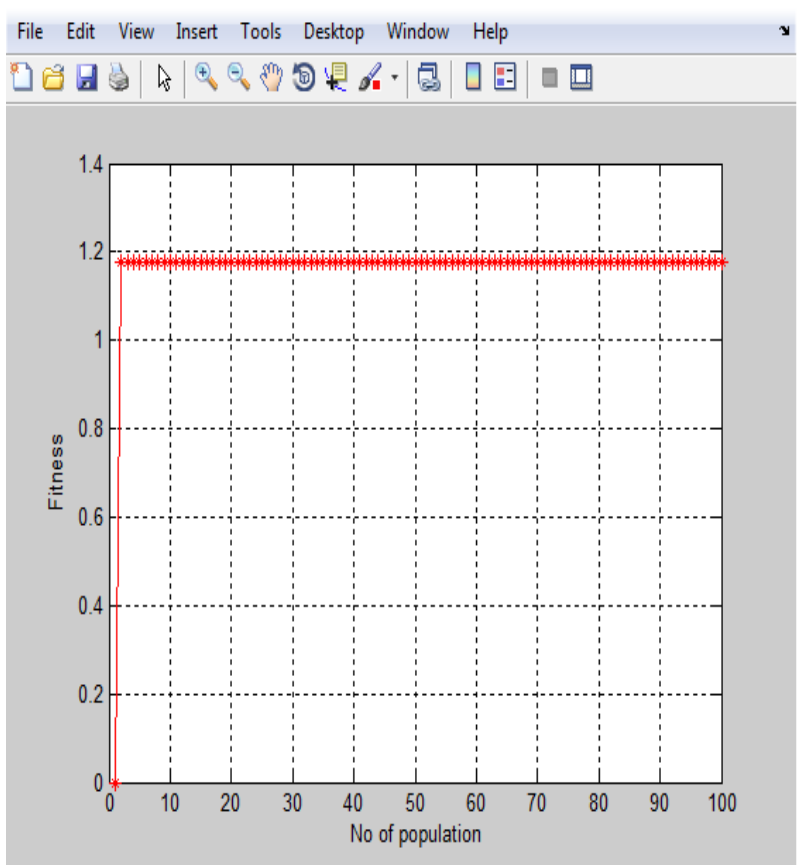

Figure 3. Convergence Characteristics of PSO PSO for three DGs for IEEE 12 Bus System

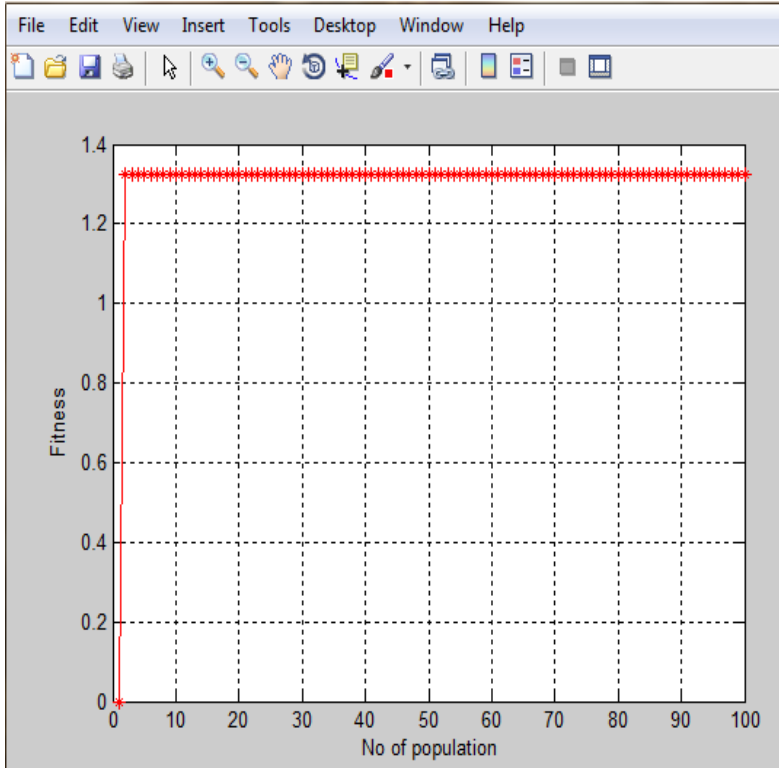

Figure 5. Convergence Characteristics of PSO PSO for Two DGs for IEEE 33 Bus System

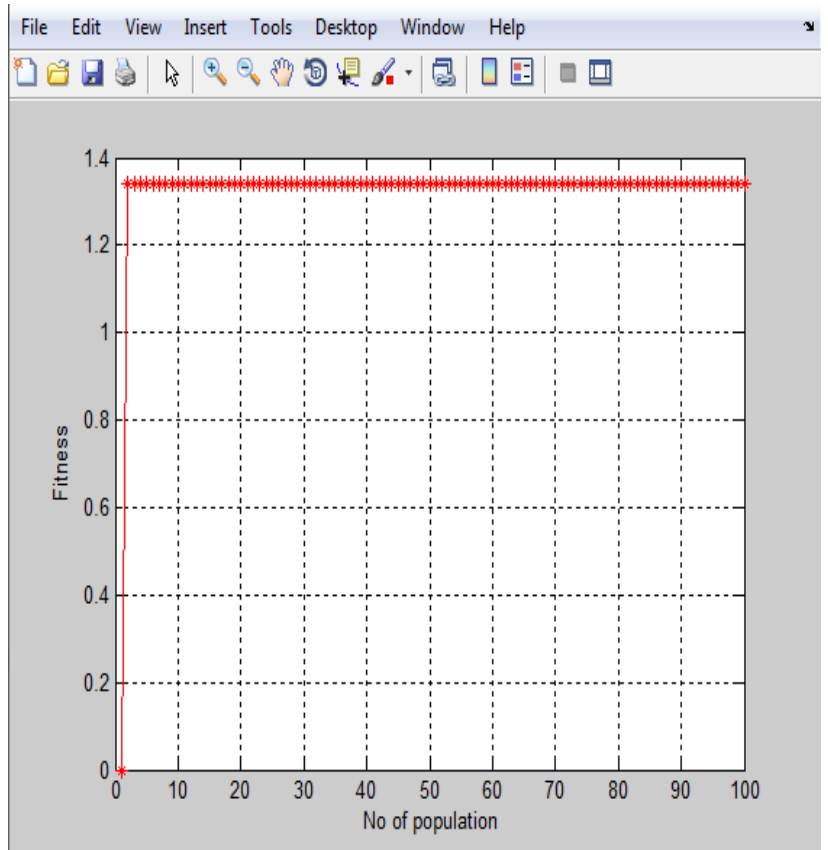

Figure 4. Convergence Characteristics of for one DG for IEEE 33 bus system

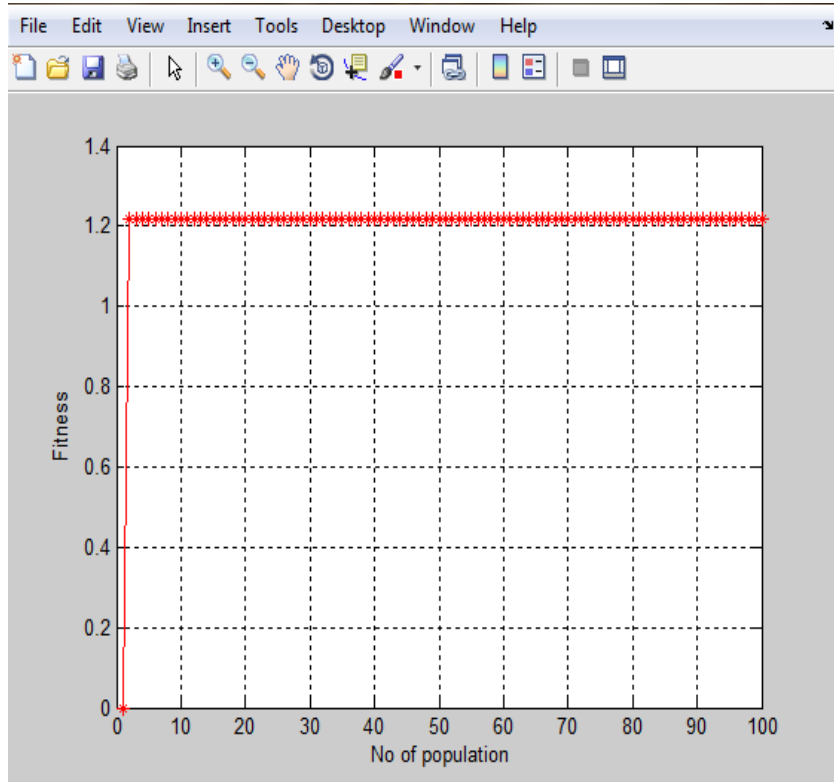

Figure 6. convergence Characteristics of for three DGs for IEEE-33 bus System

\section{Conclusions:}

In this paper, a strategic DG placement method for distribution system was presented. The presented method takes the benefits and costs of DG placement into account and tries to find the optimal types, locations and sizes for DG placement with the maximum benefit/cost ratio. A Particle swarm optimization method was employed to solve the problem. Test results shows that with proper types, sizes and installation site selection, DG is one of the best methods to improve service reliability, reduce the customer outage costs and saves the power cost. 


\section{References:}

[1]. Maurhogg, B; Wood, G., "Dispersed generation-reduce power costs and improve service reliability," IEEE rural Electric Power Conference, pp.C5/1-C5/7, 2000.

[2]. Silvestri, A.; Berizzi, A.;Buonanno, S., "Distributed generation planning using genetic algorithms," IEEE Powr Tech Budapest 99, pp.257,1999.

[3]. Dugan, R.C.; McDermott, T.E.; Ball, G. J., "Distribution Planning for distributed generation," IEEE Rural Electric Power Conference, pp.C4/1-C4/7, 2000

[4]. Rackliffe, G., "Guidelines for planning distributed generation systems," IEEE PES Society Summer Meeting, Vol.3, pp.16661667,2000

[5]. Chowdhury, A.A., Koval, D.O., "Value Based disgtribution system reliability Planning," IEEE Transactions on Industry Applications, Vol.34, No.1, Jan-Feb.1998, pp-23-29.

[6]. Teng, J.H., Lu, C.N, "Feeder Switch Relocation for Customer Interruption Costs Minimization,” IEEETrans. On Power System, Vol.17, No.1, pp. 254-259, 2002.

[7]. Kennedy J and Eberhart R,, "Particle Sarm Optimizer," IEEE International Conference on Neural Networks (Perth, Australia), IEEE Service Centter Piscataway, NJ, IV, pp1942-1948, 1995

[8]. Jen-Hao Teng, Tain-Syh Luor, "Strategic Distributed Generator Placements for service reliability improvements" in Proceedings IEEE Power Engineering Society Summer Meeting, Vol.2, Jul. 2002, pp.719-724 